\title{
ANALYSIS OF CUTTING FORCE IN THE PROCESS OF CHIPLESS FELLING WOOD
}

\author{
Pavol Harvánek, Ján Kováč, Ján Melicherčík \\ Technical University in Zvolen \\ Slovak Republic \\ (Received June 2020)
}

\begin{abstract}
This study compared the magnitude of the value of the cutting force using different tools with different thickness for different wood species with the same size. Measurements were made on wooden samples of spruce, aspen, and beech wood with dimensions $30 \times 30 \times 200 \mathrm{~mm}$ $(\mathrm{w} \times \mathrm{d} \times \mathrm{h})$. The tearing machine pushed knives with dimension $150 \times 100 \mathrm{~mm}$ and thicknesses of $4,6,8$, and $10 \mathrm{~mm}$ with a $30^{\circ}$ angle of cutting edge into the wood samples in a direction perpendicular to the fiber growth. Research shows that this angle of cutting edge is most effective for chipless cutting. The results were analysed by the Statistica 12 software. From the measurement results, for chipless wood felling is most preferred the $10 \mathrm{~mm}$ cutting knife thickness.
\end{abstract}

KEYWORDS: Chipless cutting, cutting force, tearing machine, transverse cutting, chipless felling wood.

\section{INTRODUCTION}

Wood chipless cutting is understood as a technological process by which a single-wedge knife operates to obtain a desired shape of the wood. Wood is split into smaller parts without the generation of waste in the form of chips (Koren 1983). Chipless cutting in the forest harvesting process is mainly used by machines intended for tree delimbing (Hatton et al. 2015, Hatton et al. 2017). However, more often, chipless cutting of wood is used in chipless cutting heads in single-operation machines performing only the tree cutting. They are included in machine assemblies together with processors. These machine assemblies are able to further process sawn wood into chips for cellulose industry, oriented strand boards' production, but mainly for products of bioenergy because currently renewable energy sources are one of the most prevalent topics in the environmental industry (Jylha and Bregstorm 2016, Nathan and Hanzelka 2016, Stochlová et al. 2019). 
Especially in older types of chipless cutting heads, a knife cutting device with one fixed and the other movable knife, or with two moving floating knives, can be used to maximize $25 \mathrm{~cm} \log$ cutting (Kováč et al. 2017). Chipless cutting heads are used to cut logs up to $30 \mathrm{~cm}$ in diameter.

During the cutting process, hydraulic control gripping arms push the trunk into the cutting knife. The principle of a chipless cutting head is based on pushing the cutting wedge (cutting tool) into the trunk in a transverse direction to the fiber growth (Fig. 1). The longitudinal cutting is directly used for wood splitting (Minárik et Hricová 2015, Pichler et al. 2018, Wegener et Wegener 2013, Kováč et al. 2014 )

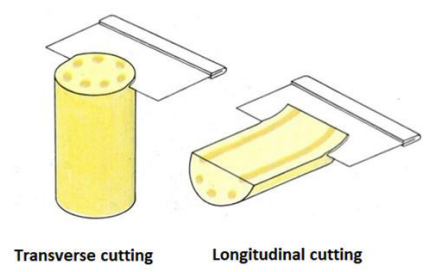

Fig. 1: Transverse cutting section.

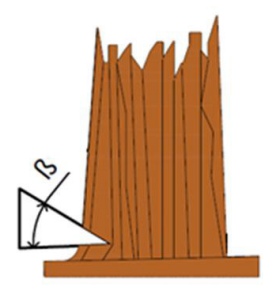

Fig. 2: Chipless cutting scheme $\beta$ - cutting wedge angle.

Chipless wood cutting is defined as the penetration of the cutting tool into the wood in the direction perpendicular to the growth of the fibers. Chipless cutting of wood with a knife is based on the ability of wood to deform. The wood shows a relatively small deformation resistance when pushing the wedge into it. When pushing a cutting tool into the wood, the cutting edge interrupts the bonding between the fibers, leaving no waste chips and a cutting gap is equal to zero (Marko and Holík 2000). An illustration of a basic schematic of a chipless cutting by a single-action flat knife is shown in (Fig. 2).

\section{MATERIAL AND METHODS}

Measurements were conducted with a tearing machine Testometric M500-100CT operating with a force up to $100 \mathrm{kN}$, with cutting speed $50 \mathrm{~mm} \cdot \mathrm{min}^{-1}$ (Testometric Co., Ltd., Rochdale, England), an evaluation device (WinTestTM Analysis, Labor machine s.r.o, Opava, Czech Reublic), and a sample material from spruce (Picea abies), beech (Fagus sylvatica) and aspen wood (Populus tremula) from University Forestry Enterprise of Technical University in Zvolen, Slovakia. The results from the WinTest ${ }^{\mathrm{TM}}$ software were processed in the Statistica 12 statistical software from TIBCO Software Inc., Palo Alto, CA, USA.

The tearing machine Testometric M500-100CT was equipped with a gripping tool. Cutting knives with different thickness were inserted into the gripping tool. The strength class 12.9 cylindrical head screws were used to fix cutting knives into the gripping tool. The gripping tool used for measurements is shown in (Fig. 3).

Steel 19191 (STN 41 9191) or DIN C105W1 (Slavia Steel s.r.o, Rimavská Sobota, Slovakia) was used for cutting knives. Steel 19191 is suitable for smaller-shaped cutting tools for wood, rubber, and plastics. The mechanical properties of steel are described in Tab. 1. Steel 19191 is suitable for use in mowing machines but also for use in the cutting process due to high hardness and wear resistance (Falat et al. 2019, Kalincová et al. 2018, Ťavodová et al. 2106). 


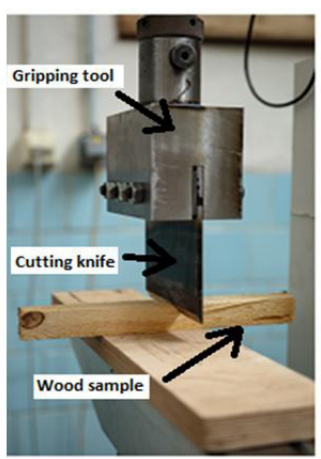

Fig. 3: Gripping tool for cutting knifes.

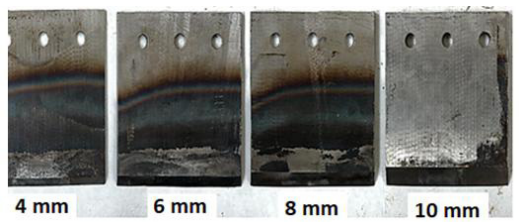

Fig. 4: Types of cutting knifes with different thickness.

Tab. 1: Mechanical properties of DIN C105W1 steel.

\begin{tabular}{|c|c|c|}
\hline Parameter & Value & Units \\
\hline Young's modulus & 200000 to 200000 & $\mathrm{MPa}$ \\
\hline Tensile strength & 650 to 880 & $\mathrm{MPa}$ \\
\hline Elongation & 8 to 25 & $\%$ \\
\hline Fatigue & 275 to 275 & $\mathrm{MPa}$ \\
\hline Yield strength & 350 to 550 & $\mathrm{MPa}$ \\
\hline
\end{tabular}

For this research, four knives were made. Cutting knives are flat, single acting knives with a thickness of $s=4,6,8$, and $10 \mathrm{~mm}$ and a cutting edge angle $\beta=30^{\circ}$. According to Johansson (1996), Hirai et al. (1996), Marko (1996), this cutting edge angle is the most effective. The cutting edge of the cutting knife was quenched and tempered to the 56 HRC. The knives that were used for the experimental measurement are shown in (Fig. 4).

Measurements were made on wood samples from spruce wood, beech wood, and aspen wood with dimensions of $30 \times 30 \times 200 \mathrm{~mm}(\mathrm{w} \times \mathrm{d} \times \mathrm{h})$.

\section{RESULTS}

The criteria used for the analysis was the maximum force required to cut the wood sample in a direction perpendicular to the growth of the tree fibers. For each tree sample, a graph of $95 \%$ confidence interval for mean values of cutting force depending on knife thickness was produced separately where it was possible to separately observe the amount of cutting force for each cutting knife thickness. A similar measurement theory was used by Kováč et al. (2014), Kuvik et al. (2017, 2018) and Krilek et al. (2015). Fig. 5 shows the varying magnitude of the cutting force for the cutting knife with different thickness in spruce wood. The smallest cutting force occurred when the $4 \mathrm{~mm}$ thick cutting knife was used. 
Box and Whisker Plot

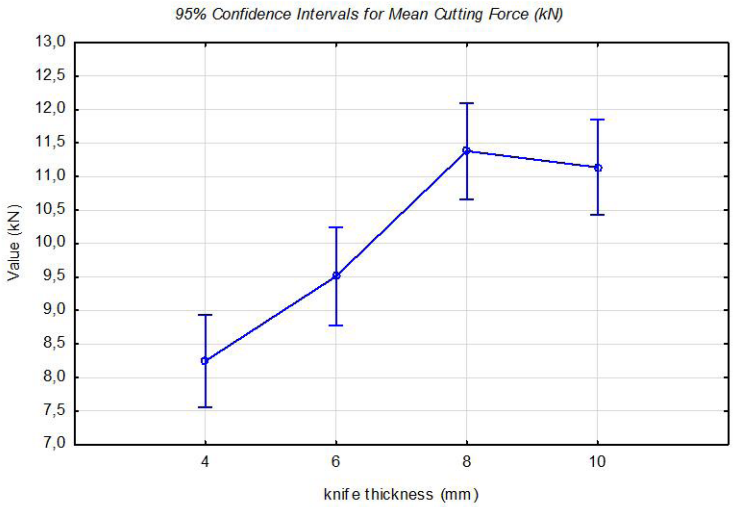

Fig. 5: Graph of 95\% confidence intervals for mean values of cutting force depending on knife thickness for spruce wood.

However, at this thickness, the strength of the knife decreased, and use in practice would not meet the economical and safety requirements. The largest cutting force was achieved at an $8 \mathrm{~mm}$ thickness. The cutting force reduced for the cutting knife with $10 \mathrm{~mm}$ thickness compared to the $8 \mathrm{~mm}$ cutting knife. Based on these observations, it is advantageous to use a $10 \mathrm{~mm}$-thick cutting knife for felling spruce wood due to the smaller cutting strength and greater knife strength.

Box and Whisker Plot

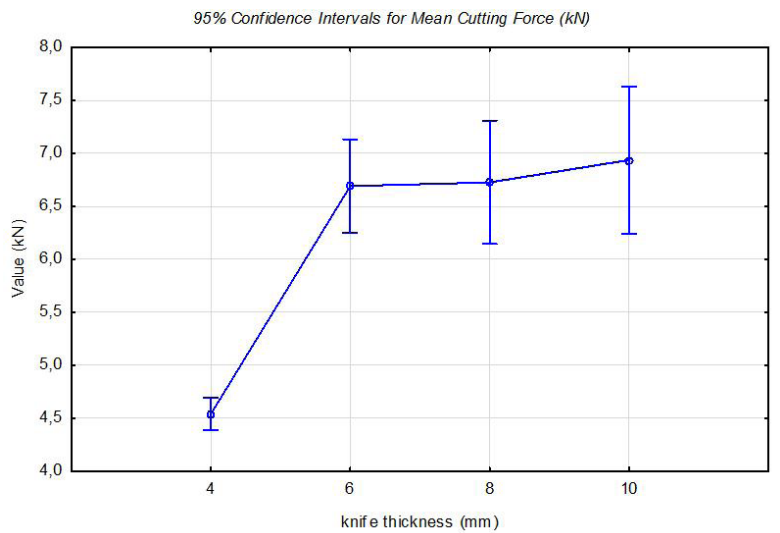

Fig. 6: Graph of 95\% confidence intervals for mean values of cutting force depending on knife thickness for aspen wood.

It is evident from (Fig. 6) that the smallest cutting force was measured with the $4 \mathrm{~mm}$ knife, but it is interesting that there was not a large difference in the size of the cutting force between the cutting knives with $6 \mathrm{~mm}$ and $10 \mathrm{~mm}$ thickness. The difference between the $6 \mathrm{~mm}$ and $8 \mathrm{~mm}$ cutting knife was not statistically significant. 
Box and Whisker Plot

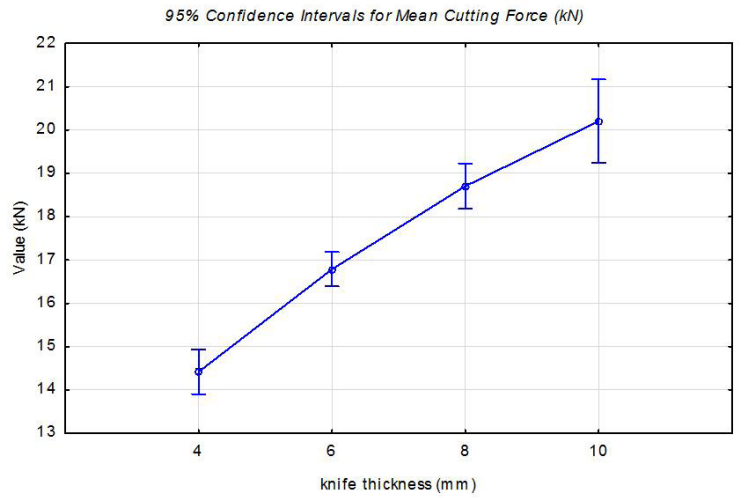

Fig. 7: Graph of 95\% confidence intervals for mean values of cutting force depending on knife thickness for beech wood.

From (Fig. 7), the amount of cutting force for beech wood can be observed. The smallest cutting force was achieved using a $4 \mathrm{~mm}$ cutting knife. When using a $10 \mathrm{~mm}$ cutting knife, the maximum cutting force was achieved. It is preferable to incline to the cutting knife with a thickness of $10 \mathrm{~mm}$ despite a larger cutting force because of its increased resistance to damage. The research showed that the greatest cutting force was measured at a $10 \mathrm{~mm}$-thick cutting knife, for this reason the use is inefficient in practice, but the strength of the cutting knife is best at a thickness of $10 \mathrm{~mm}$. Therefore, from the perspective of the author, it is better to use a $10 \mathrm{~mm}$ cutting knife.

\section{DISCUSSION}

From the measurements according to (Fig. 8), it was found that the greatest forces were used to cut beech wood. These results are identical to that of Marko's (1996) study (Marko 1996). Furthermore, it was found that for a $10 \mathrm{~mm}$ knife, the beech and aspen samples increased the scattering of force value. Again, these results are similar to the study by (Marko 1996). Results from this study indicate that it is most advantageous to use a $10 \mathrm{~mm}$ thick cutting knife. The maximum cutting force for spruce wood was less with $10 \mathrm{~mm}$ knife than with the $8 \mathrm{~mm}$ knife. For the aspen samples, the difference in the cutting force was not significant for the $6 \mathrm{~mm}$ and $8 \mathrm{~mm}$ knife. Therefore, it is preferable to use the $10 \mathrm{~mm}$ cutting knife for its increased strength.

Based on a literature search Mikleš et al. (2012) say that the results of chipless cutting research showed that the cutting force when the knife penetrates into the wood initially increases linearly but then decreases to zero where the maximum cutting force corresponds to a knife penetration depth of 0.55 to $0.80 \%$ diameter of the cut sample. 


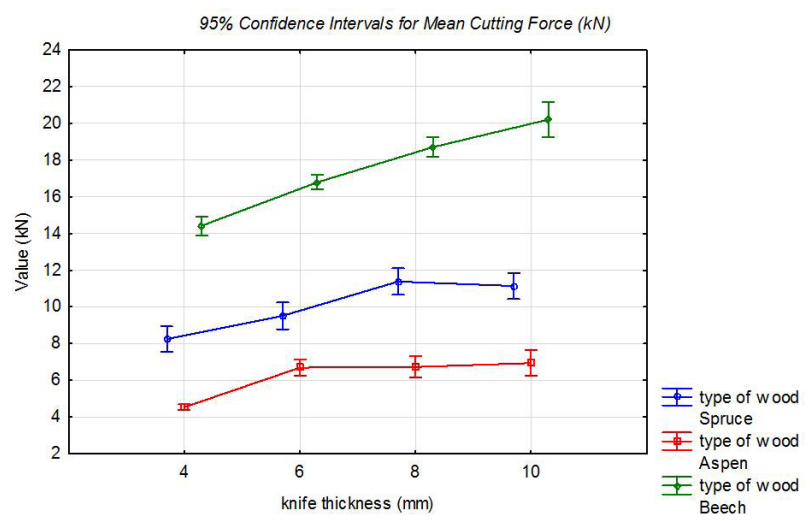

Fig. 8: Graphs of $95 \%$ confidence intervals for mean values of cutting force depending on knife thickness for spruce, beech and aspen wood.

However, this statement applies to wood samples of circular cross-section. In the case of our measurement, it was found that the maximum cutting force with $10 \mathrm{~mm}$ cutting knife for all samples was reached just before end of cutting the sample, which is also shown in Fig. 9. This statement is identical with the author (Melicherčík et al. 2020, Harvánek et al. 2019).

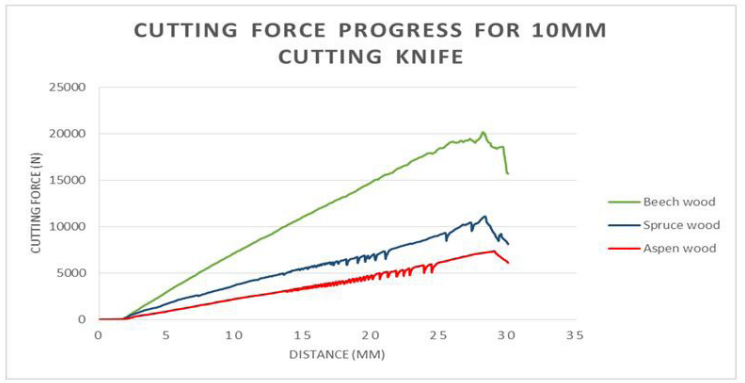

Fig. 9: Dependence of the cutting force on the distance of cutting knife.

\section{CONCLUSIONS}

Recently, when great emphasis is placed on the protection of the environment, the method of wood chipless cutting comes to the forefront. The purpose of this article was to determine the effect of the thickness of the cutting knife on the amount of cutting force required to cut the sample in a direction perpendicular to the fiber growth. Different wood samples of the same size were used for the experiment. From this analysis and experimental measurement, it has been shown that varying thickness of the cutting knife has a statistically significant effect on the size of the cutting force. The size of this cutting force is always different with the above-mentioned tree species. From the results of experimental measurement, it can be argued that for chipless wood cutting of spruce, beech or aspen It is best to use a $10 \mathrm{~mm}$ knife. The maximum cutting force for 
spruce was $15.12 \mathrm{kN}$ with $10 \mathrm{~mm}$ cutting knife compared to the $15.76 \mathrm{kN}$ at $8 \mathrm{~mm}$ cutting knife. In case of aspen wood maximum cutting force was $11.39 \mathrm{kN}$ for $10 \mathrm{~mm}$ knife thickness. In beech wood, the use of a $10 \mathrm{~mm}$ cutting knife is more advantageous mainly because of its strength, even if the cutting force is the highest.

\section{ACKNOWLEDGEMENT}

This article was created during the processing of the project VEGA no. 1/0642/18 "Analysis of the impact of structural parts of forestry mechanisms in the forest environment in terms of energy and ecology" and the project IPA 19/2020 "Research of the cutting mechanism of the cutting head in the area of chipless cutting of woody plants".

\section{REFERENCES}

1. Falat, L., Džupon, M., Ťavodová, M., Hnilica, R., Luuptáčiková, V., Čiripová, L., Homolová, V., Durišinová, K., 2019: Microstructure and abrasive wear resistance of various alloy hardfacings for application on heavy-duty chipper tools in forestry shredding and mulching operations. Materials 12(13): 1-16.

2. Harvánek, P., Kováč, J., 2019: Analysis of cutting forces in transverse cutting of spruce wood. In: Proceeding of XXI International conference of young scientists. Slovak University of Agriculture in Nitra, Faculty of Engineering, Pp 36-44.

3. Hatton, B., Bouzgarrou, J., Fauroux, V., Gagnol, V., Gogu, G., 2017: An approach for modelling harvester. Springer International Publishing AG, Pp 133-141.

4. Hatton, B., Pot, G., Bouzgarrou, B., Gagnol, V., and Gogu, G., 2015: Experimental determination of delimbing forces and deformations in hardwood harvesting. Croatian Journal of Forest Engineering 36(1): 43-53.

5. Hirai, T., Yoshida, S., Tsuchihashi, H., 1996:. Cutting performances of limbing knives of $\log$ harvesters. 1. Effect of wedge angles on cutting resistance of single-tapered knives. Journal of the Japan Wood Research Society 42(3): 258-263.

6. Johansson, J., 1996: Case studies on farm tractors as base machines for single-grip thinnings harvester heads. Forestry: An International Journal of Forest Research 69(3): 229-244.

7. Jylha, P., Bregstorm, D., 2016: Productivity of harvesting dense birch stands for bioenergy. Biomass and Bioenergy 88: 142-151.

8. Kalincová, D., Ťavodová, M., Jakubéczyová, D., 2018: Quality evaluation of the coatings and its influence on the wood machining tool wear. In Manufacturing Technology 18(4) : 578-584.

9. Koreň, J., 1983: Chipless wood cutting. Technical University in Zvolen, Slovakia, 105 pp.

10. Kováč, J., Krilek, J., Jobbágy, J., Dvořák, J., 2017: Technique and mechanization in forestry. Technical University in Zvolen, Slovakia, 354 pp.

11. Kováč, J., Krilek, J., Kučera, M., Barcík, S., 2014. The impact of design parameters of a horizontal wood splitter on splitting force. Drvna Industrija 65(4): 263-271.

12. Kováč, J., Krilek, J., Kučera, M., Barcík, Š., 2014: The impact of design parameters of a horizontal wood splitter on splitting force. Drvna industrija 65(4): 263-271.

13. Krilek, J., Kováč, J., Barcík, Š., Svoreň, J., Štefánek, M., Kuvik, T., 2015: The influence of chosen factors of a circular saw blade on the noise level in the process of cross cutting wood. Wood Research 61(3): 475-486. 
14. Kuvik, T., Krilek, J., Kováč, J., 2018: Research of cutting mechanisms in cross-cutting of wood Technical University in Zvolen, Slovakia, $161 \mathrm{pp}$.

15. Kuvik. T., Krilek. J., Kováč. J., Štefánek. M., Dvořák. J., 2017: Impact of the selected factors on the cutting force when using a chainsaw. Wood Research 62(5): 807-814.

16. Marko, J., 1996. The issue of evaluation of cutting mechanisms for educational interventions. Technical University in Zvolen, Slovakia, 50 pp.

17. Marko, J., Holík, J., 2000: Theory of wood dividing. Technical University in Zvolen, Slovakia, 66 pp.

18. Melicherčík, J., Krilek, J., Harvánek, P., 2020: Simulation of stress and strain analysis on a delimbing knife with replaceable cutting edge. BioResources 15(2): 3799-3808.

19. Mikleš, J., Mikleš, M., 2012: Design of the chucking device logs of cutting mechanism cross-cutting line. In: Chip and Chipless Woodworking Processes 2012: 239-246.

20. Minarik, M., Hricova, J., 2015: Log splitter design and construction. Drvna Industrija 66(1): 11-16.

21. Nathan, C., Hanzelka, M., 2016. Productivity and costs of utilizing small-diameter stems in a biomass-only harvest. International Journal of Forest Engineering 27(1): 43-52.

22. Pichler, P., Leitner, M., Gruen, F., 2018: Evaluation of wood material models for the numerical assessment of cutting forces in chipping processes. In: Wood Science and Technology 52: 281-294.

23. Stochlová, P., Novotná, K., Costa, M., Rodrigues, A., 2019. Biomass production of poplar short rotation coppice over five and six rotations and its aptitude as a fuel. In: Biomass and Bioenergy 122: 183-192.

24. Ťavodová, M., Krilek, J., Perec, Andrzej - Kalincová, D., Kováč, J., 2016: Analysis of the wear of saw blade teeth and the proposal of methods of increasing their wear resistance. MM science journal 2016(05): 1287-1291.

25. Wegener, J., Wegener, T., 2013: Kinematics and geometry of helical chipping with cylindrical helical blades. Transactions of the ASABE 56(4): 1291-1297.

\author{
Pavol HarváneK*, Ján Kováč, Ján Melicherčíi \\ Technical University in Zvolen \\ Faculty of Technology \\ Department of Environmental and Forestry Technology \\ ŠTUDENTSKÁ 26 \\ 96053 Zvolen \\ Slovak Republic \\ *Corresponding author: pavol.harvanek@gmail.com
}

